\title{
PERCEPÇÕES SOBRE O CERRADO ENCONTRADAS EM GRADUANDOS EM ENGENHARIAS DA UNIVERSIDADE ESTADUAL PAULISTA DE BAURU
}

\author{
Maria do Carmo Jampaulo Plácido Palhaci ${ }^{1}$, Luiz Roberto Vasques Hellmeister ${ }^{2}$, Talitha Plácido \\ Palhaci $^{3}$, Carmem Francisca Hellmeister ${ }^{4}$
}

\begin{abstract}
When we discuss environmental issues, research shows that individuals do not seem to present a genuine perception of the natural environment, which can be justified by the current context of modernity, in which the contact of many people with a natural environment is scarce and in front of this, build a perception of environment through intermediaries, such as classes, books, magazines or television. The Universidade Estadual Paulista Júlio de Mesquita Filho, located in Bauru - SP, allows its goers a direct contact with the Cerrado, since part of this biome reserve is located in the institution. This paper reports a research on perceptions related to the Cerrado, conducted with students of the first and last year of Graduation in Engineering. The aim was to investigate whether there are differences in perceptions found in beginners and senior students who attended about five years of disciplines on a campus present in the Cerrado area.

Index Terms $\rightarrow$ Search, perception, biome cerrado.
\end{abstract}

\section{INTRODUÇÃO}

A degradação do meio ambiente acentuada nos dias atuais traz profundas preocupações a respeito do porque isso acontece. Esta pesquisa buscou abranger diretamente os cursos de engenharias desta Universidade, visto serem cursos dedicados as ciências exatas que não possuem educação ambiental. A questão ecológica vem tomando corpo e se difundindo com muita rapidez, pois o comportamento agressivo do homem à natureza vem se intensificando cada vez mais, pondo em risco a própria sobrevivência humana.

Atualmente não se pode negar a importância das questões ambientais nas mais diferentes esferas da sociedade como agricultura, saneamento, urbanismo, educação, economia e política (FRACALANZA,1992).

Esta pesquisa busca analisar o conhecimento dos Universitários visto que no Ensino médio os conceitos ecológicos são exemplificados por animais e plantas não característicos do Brasil, mas característicos de outros países. Isso como é a fauna propicia aos alunos uma noção distorcida de e flora brasileira. Faltam também ilustrações dos conteúdos estudados, o que pode dificultar a visualização, o entendimento e o interesse dos alunos sobre o assunto abordado. No contexto escolar o entendimento desses conceitos científicos que a Ecologia aborda é imprescindível. O aluno em formação precisa dominar e apropriar-se da linguagem e desses conceitos científicos para desenvolver atitudes e práticas criticas e responsáveis frente ao uso de recursos naturais, assim como estarem aptos a lidar com os problemas ambientais tão presentes no nosso dia a dia.

\section{Cerrado}

No domínio do cerrado predomina o bioma cerrado, mas ali também estão representados outros tipos de biomas como veredas, matas galeria e matas mesófilas de interflúvio. O clima predominante desse domínio é o tropical sazonal, de inverno seco e a temperatura média anual fica em torno de $22-23^{\circ} \mathrm{C}$ (COUTINHO, 2000).

O relevo do domínio cerrado estende-se por imensos planaltos ou chapadões, e é, em geral, bastante plano ou suavemente ondulado. Os solos são profundos, porosos, permeáveis, bem drenados e, por consequiência, profundamente lixiviados. Sua capacidade de retenção de água é relativamente baixa e seu teor de matéria orgânica pequena. São bastante ácidos, devido principalmente aos altos níveis de $\mathrm{Al}+{ }^{3}$ e também aos íons $\mathrm{Fe}$ e $\mathrm{Mn}$ que contribuem para sua toxidez. São profundamente distróficos, e por conseqüência, impróprios para agricultura (COUTINHO, 2000).

Do ponto de vista fisionômico, o cerrado apresenta dois extremos: o campo limpo onde há predomínio do componente herbáceo-subarbustivo; e o cerradão, fisionomia na qual predomina o componente arbóreoarbustivo. As demais fisionomias encontradas-campo sujo, campo cerrado, cerrado (sentido restrito) - podem ser consideradas ecótonos entre o campo limpo e o cerradão (COUTINHO, 1978).

A vegetação arbórea e arbustiva do cerrado apresenta como principais características os troncos e ramos tortuosos,

\footnotetext{
${ }^{1}$ Maria do Carmo Jampaulo Plácido Palhaci, Professora Assistente Doutora, Universidade Estadual Paulista - UNESP - Campus de Bauru , SP, Brazil, palhaci@faac.unesp.br

${ }^{2}$ Luiz Antonio Vasques Hellmeister Professor Assistente Doutora da Universidade Estadual Paulista, UNESP - Campus de Bauru hellmeister@faac.unesp.b ${ }^{3}$ Talitha Plácido Palhaci, Doutoranda da Pós-Graduação em Ensino para a Ciência da Faculdade de Ciências da Universidade Estadual Paulista - UNESPCampus de Bauru, tah_palhaci@yahoo.com.br

${ }^{4}$ Carmem Francisca Hellmeister , Professora Assistente Doutora pela Universidade Estadual Paulista - UNESP - Campus de Bauru,carmenfl @ feb.unesp.br
} 
súber espesso, macrofilia, esclerofilia e um sistema subterrâneo com longas raízes pivotantes, que permitem que a planta se abasteça de água até mesmo em épocas secas (COUTINHO, 2000).

A fauna de invertebrados do bioma cerrado é pouco conhecida. Entre os vertebrados encontrados em áreas do cerrado estão a jibóia, a cascavel, várias espécies de jararacas, o lagarto teiú, a ema, a siriema, a curicaca, o urubu comum, o urubu caçador, o urubu rei, araras, tucanos, papagaios, gaviões, o tatu peba, o tatu galinha, o tatu canastra, o tamanduá-bandeira, o tamanduá-mirim, o veadocampeiro, o cateto, a anta, o cachorro-do-mato, o cachorrodo-mato vinagre, o lobo guará, a jaratataca, o gato mourisco e raramente a onça-parda e a onça pintada (COUTINHO, 2000).

Uma das poucas áreas de cerrado protegidas no estado de São Paulo é o fragmento florestal presente no município de Bauru. A UNESP - Universidade Estadual Paulista é uma das instituições responsáveis pelos cuidados de parte desse fragmento. A área pertencente ao Campus é de 387,20 hectares sendo que 132,0126 hectares foram destinados a ser “Área de Reserva Legal” (FARACO, 2007).

A área pertencente ao Campus da UNESP de Bauru tem seu marco inicial junto à cerca do lado esquerdo da Rodovia Estadual Jaú-Ipauçu (Rodovia Comandante João Ribeiro de Barros - SP 225), próxima das coordenadas $22^{\circ} 20^{\prime} \mathrm{S}$ e $49^{\circ}$ $00^{\prime} \mathrm{W}$, a 580 metros de altitude, na região sudeste da cidade próxima ao perímetro urbano. Suas divisas são a área remanescente da Prefeitura Municipal de Bauru (Zoológico Municipal e Jardim Botânico), o jardim Marambá, o Jardim Mary e o loteamento Santos Dumont (FARACO, 2007).
A fisionomia deste cerrado, no geral, se assemelha ao cerradão, pois apresenta árvores entre $4 \mathrm{~m}$ e $6 \mathrm{~m}$, sendo poucas emergentes que atingem até $19 \mathrm{~m}$ de altura. Essas árvores apresentam dossel contínuo na sua maior parte e descontínuo em raros pontos, propiciando condições de luminosidade no estrato inferior (FARACO, 2007).

\section{METODOLOGIA DE PESQUISA}

A metodologia utilizada nesta pesquisa é considerada quantitativa e qualitativa visto que foram colhidas opiniões através de questionários com perguntas fechadas e abertas.

O público utilizado foram estudantes dos cursos de Engenharias da UNESP - Campus de Bauru, visto os mesmos não possuírem em seu programa de graduação , nenhuma disciplina que se refira ao meio ambiente e a Universidade estar localizada exatamente em um grande campo de Cerrado.

\section{DESENVOLVIMENTO DO TRABALHO}

A elaboração de um questionário foi o primeiro passo da pesquisa: Responderam ao questionário abaixo, 46 alunos do primeiro e do quarto ano do curso de Engenharia Elétrica.

\section{Questionário - percepções sobre o Cerrado de Bauru}

\section{Já realizou trilha por região de Cerrado?}

$\begin{array}{llcc}\text { - } & \text { Sim. } & \text { Especifique o } \\ \text { local_ b) ( )Não }\end{array}$

O questionário foi respondido por 46 alunos do Curso de Engenharia Elétrica da UNESP - Campus de Bauru.

Em resposta a primeira questão, 37 alunos nunca fizeram trilha e 09 alunos já fizeram, sendo que :

Do primeiro ano: 19 nunca fizeram e 04 fizeram.Do quarto ano: 18 nunca fizeram e 05 fizeram.

\section{Você passou a maior parte de sưa vida morand}

em um ambiente: sos

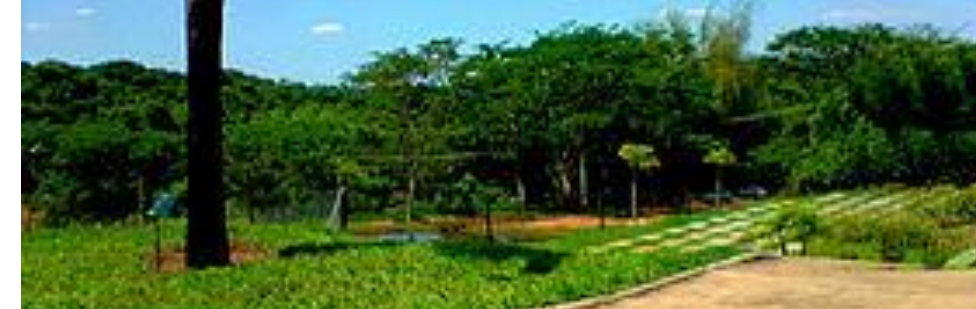

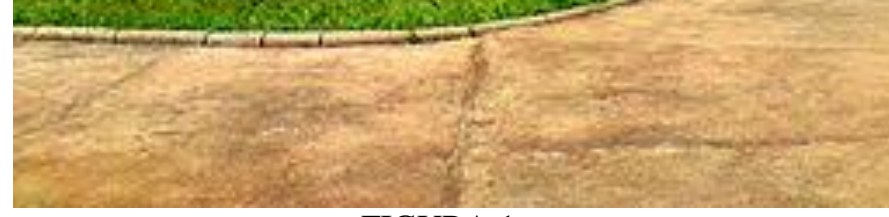

FIGURA 1

JARDIM BOTÂNICO DE BAURU.

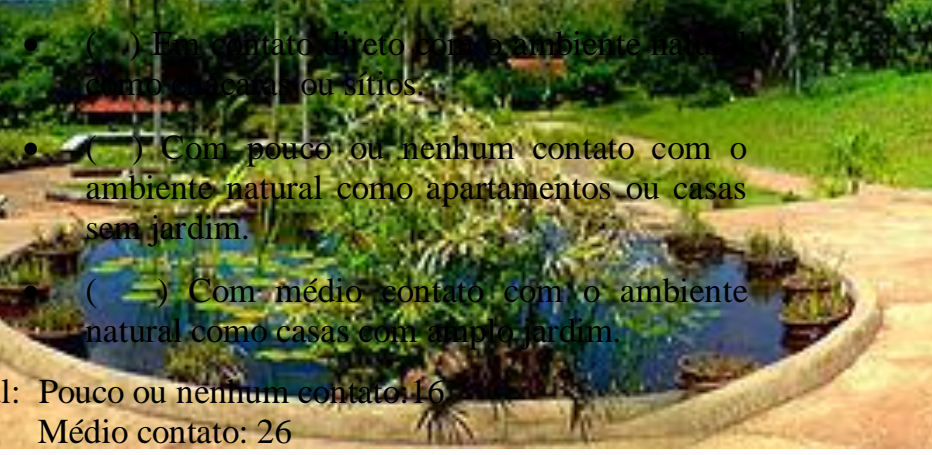

Contato direto: 04

Do primeiro ano: Pouco ou nenhum contato: 09

Médio contato: 13 
Contato direto: 01

Do quarto ano: Pouco ou nenhum contato: 07

Médio contato: 13

Contato direto: 03

3. Cite qualquer tipo de características sobre o bioma Cerrado, podendo estar relacionada a seu solo, seu clima, sua vegetação, sua fauna, sua relação com fogo, ou outro. Se necessário utilize o espaço no verso da folha. Se não se lembrar ou não souber, deixe o espaço em branco.

Nesta questão percebeu-se que os conhecimentos são similares no primeiro e quarto anos do curso. Destaca-se, entretanto que os alunos do primeiro ano responderam as questões, preocupando-se em acrescentar comentários particulares enquanto que os alunos do quarto ano foram extremamente objetivos. As principais características citadas pelos alunos foram:

Solo pobre e ácido, clima quente e seco.

A vegetação é retorcida, rasteira e de médio porte.

O fogo caso se inicie possui facilidade de se alastrar.

A fauna é rica e constituída de animais de pequeno porte.

4. Cite um nome (popular ou científico) de uma planta encontrada no bioma Cerrado. Se não se lembrar ou não souber, deixe o espaço em branco.

As respostas fornecidas pelos alunos do primeiro ano citaram maior diversidade de flora que as respostas dos alunos do quarto ano onde a maioria deixou esta resposta em branco:

Primeiro ano: Foram bastante citados: Ipê, Ipê amarelo, goiabeira, gabirobeira, amendoim, cacto, jacarandá, cajueiro, colonhão,cascudo, taberia chysotricha.

Quarto ano: gramíneas, guariroba, cacto.

5. Cite um nome (popular ou científico) de um animal encontrado no bioma Cerrado. Se não se lembrar ou não souber, deixe o espaço em branco.

As respostas fornecidas pelos alunos do primeiro ano citaram maior diversidade de fauna que as respostas dos alunos do quarto ano.

Primeiro ano: grande diversidade: siriema, lobo guará, tamanduá-bandeira, lagarto, lobo, veado, onça pintada, anta, capivara, jaguatirica, lobo guará, cachorro do mato, coiotes, gavião carcará e tatu-bola.

Quarto ano: Pouca diversidade: Lobo guará, tamanduá, capivara, cobra e onça pintada.

6. Leia a seguir um trecho retirado de um artigo publicado por Tayani Abib
"Trata-se da Lei Estadual do Cerrado, implantada em 2009, cujo objetivo é a proteção desse bioma natural. A lei nega a autorização de qualquer forma de desmatamento quando a vegetação abrigar espécies da flora e da fauna silvestres ameaçadas de extinção ou se exercer a função de proteção de mananciais e recarga de aquíferos.

São ainda definidas exceções para casos de obras de utilidade pública e interesse social, nos quais a supressão é permitida. No entanto, a área desmatada terá de ser compensada. No perímetro urbano, será preciso manter de $20 \%$ a $50 \%$ da vegetação nativa. Em regiões rurais, a supressão deve ser compensada em uma área quatro vezes maior que a original. É preciso ressalvar, ainda, que a autorização para o desmatamento da vegetação depende dos estudos e relatórios realizados pelo órgão competente, a Companhia de Tecnologia de Saneamento Ambiental (CETESB)".

A seguir reflita e responda - $O$ que você pensa sobre a ocupação das áreas de Cerrado bauruenses por empresas para a construção ou para a plantação de monoculturas?

As respostas dos alunos do primeiro e quarto ano se mostraram desfavoráveis em relação à ocupação das áreas do cerrado bauruense. Poucos alunos apontaram que o reflorestamento pode ser uma solução dependendo, entretanto, de fiscalização rigorosa.

\section{CONCluSÃo}

Tomando-se como referência o fato da maior parte da população brasileira viver em cidades, observa-se uma crescente degradação das condições de vida, refletindo uma crise ambiental. Este fato é percebido pelas respostas dos alunos onde a maioria nunca participou de trilhas pela natureza e moram em locais que apresentam médio contato com a mesma.

Em relação ao conhecimento de fauna e flora, é conveniente ressaltar o fato que os alunos do primeiro ano conhecem maior diversidade, talvez pelo fato de terem prestado vestibulares recentemente e estes conhecimentos ainda estão nítidos em suas memórias; enquanto que no quarto ano, os alunos já preocupados com o início da nova carreira, não demonstraram o conhecimento já adquiridos em anos anteriores em épocas de vestibulares. Isto nos remete a uma necessária reflexão sobre os desafios para mudar as formas de transmitir estes conhecimentos para que os mesmos não sejam esquecidos com o passar dos anos. Percebe-se então que o conhecimento através da necessidade de ser aprovado em concursos ou vestibular não é o ideal porque logo é esquecido. O aluno deve vivenciar o seu meio ambiente junto aos ensinamentos recebidos. 
Faz-se necessário então uma continuação de conhecimentos a ser transmitida, através de uma ou mais disciplinas que sejam relacionadas ao meio ambiente porque o futuro engenheiro deve se preocupar não somente com as construções bem feitas, mas que as mesmas sejam realizadas em meios favoráveis a vida no meio ambiente onde com certeza o ser humano alcançará uma melhor qualidade de vida.

Refletir sobre a complexidade ambiental abre uma estimulante oportunidade para compreender a gestação de novos atores sociais que se mobilizam para a apropriação da natureza, para um processo educativo articulado e compromissado com a sustentabilidade e a participação, apoiado numa lógica que privilegia o diálogo e a interdependência de diferentes áreas de saber.

\section{REFERENCES}

[1]FRACALANZA, D.C. Crise ambiental e ensino de Ecologia: o conflito na relação homem mundo natural. 1992. 212f. Tese (Doutorado em Educação) - Faculdade de Educação, Universidade Estadual de Campinas, Campinas, 1992.

[2] COUTINHO, L.M. O bioma cerrado. In: KLEIN, A.L. (org.). Eugen Warming e o cerrado brasileiro um século depois. São Paulo: Unesp, 2000. p. 77-91.

[3] COUTINHO, L. M. O conceito de cerrado. Revista Brasileira de Botânica. v.1, n.1, p.17- 23.1978.

[4] FARACO, A.G. Composição florística e estrutura fitossociológica de uma área de cerrado pertencente ao Campus de Bauru da Universidade Estadual Paulista UNESP, SP. 2007. 112f. Dissertação (Mestrado em Botânica) - Instituto de Biociências, Universidade Estadual Paulista, Botucatu, 2007.

[1] http://programapibicjr2010.blogspot.com.br/2011/04/diferenca-entrepesquisa-qualitativa-e.html 